\title{
REVISITING AVICENNA'S \\ (AD 980-1037) ANATOMICAL CONCEPTS \\ OF THE MUSCULOSKELETAL AND PERIPHERAL NERVOUS SYSTEMS IN THE CANON OF MEDICINE
}

\author{
RAZMATRANJE AVICENINIH (980. - 1037.) \\ ANATOMSKIH POJMOVA MIŠIĆNO-KOŠTANOG \\ I PERIFERNOG ŽIVČANOG SUSTAVA \\ U KANONU MEDICINE
}

\author{
Pedzisai Mazengenya", Rashid Bhikha, ***
}

\begin{abstract}
SUMMARY
Avicenna, as he is known in the West, was a famous Persian Muslim physician and influential philosopher-scientist of the medieval Islamic world. He wrote and compiled the Canon of Medicine text, a book which was adopted as the main text of medicine at the most Persian and Western universities. The book consists of basic medical sciences, applied clinical sciences and pharmacology. In the current study, we present an analysis of the anatomy of the musculoskeletal and peripheral nervous systems as viewed by Avicenna in the Canon of Medicine, and compare them with the relevant modern literature.

Keywords: Avicenna, Ibn Sina, musculoskeletal system, peripheral nervous system, cranial nerves, joints

School of Anatomical Sciences, The University of the Witwatersrand, Faculty of Health Sciences, Johannesburg, South Africa.

Ibn Sina Institute of Tibb, Johannesburg, South Africa.

Correspondence Address: Pedzisai Mazengenya, School of Anatomical Sciences, The University of the Witwatersrand, Faculty of Health Sciences, 7, York Road, Parktown, Johannesburg, South Africa.E-mail: pedzisai.mazengenya@wits.ac.za.
\end{abstract}




\section{INTRODUCTION}

The musculoskeletal and peripheral nervous systems occupy a crucial position in modern orthopedics, forensic anthropology and regenerative medicine. To reiterate their importance in medical history, numerous historical scientists including early Egyptians, Greeks, Romans and Persians described the anatomy and management of disease conditions associated with each region of the body. It is prudent to say that modern scientific achievements are indebted to the past [I, 2]. The objective of the current research is to investigate the accuracy and relevance of Avicenna's (AD 980-1037) anatomy of the musculoskeletal and peripheral nervous system and compare it to modern anatomy discourse.

Analysis of Avicenna's anatomical concepts as presented in the Canon of Medicine has become increasingly popular and several researches have been published to date $[2-14]$. Common findings from these researches point out to the relevance of Avicenna's anatomy and its place in revolutionizing modern medicine. Avicenna adopted the practical approach towards the descriptions of the human body and the associated diseases [I, 2, I5, I6], which is the main scientific approach in modern medicine. In his treatise, Avicenna emphasized the importance of anatomy of the human body and encouraged physicians to consider the normal anatomy of organs in their diagnosis [I, 2, $9,16,17]$. The current review was therefore intended to analyse and compare Avicenna's treatise on the anatomy of musculoskeletal and peripheral nervous systems presented in volume one and three of the Canon of Medicine [I8] (and translated versions into English) [19, 20] with modern descriptions in extant medical anatomy literature. In addition Avicenna's description of anatomy within the context of temperament, structure and function are highlighted.

\section{Avicenna And the Canon of Medicine}

Avicenna (Ibn Sina) was born in AD 980, near Bukhara, Iran (now in Uzbekistan) and died in ro37 in Hamadan, Iran. He was a famous Persian Muslim physician and influential philosopher-scientist of the medieval Islamic world [2I]. Avicenna was a gifted child who educated himself in various fields including medicine and philosophy. By the age of Io, Ibn Sina had become an expert in the study of the Quran and different earth sciences. He studied philosophy by reading various Greek, Muslim, and other texts and learned metaphysics and logic under teachers which he later surpassed [21]. 


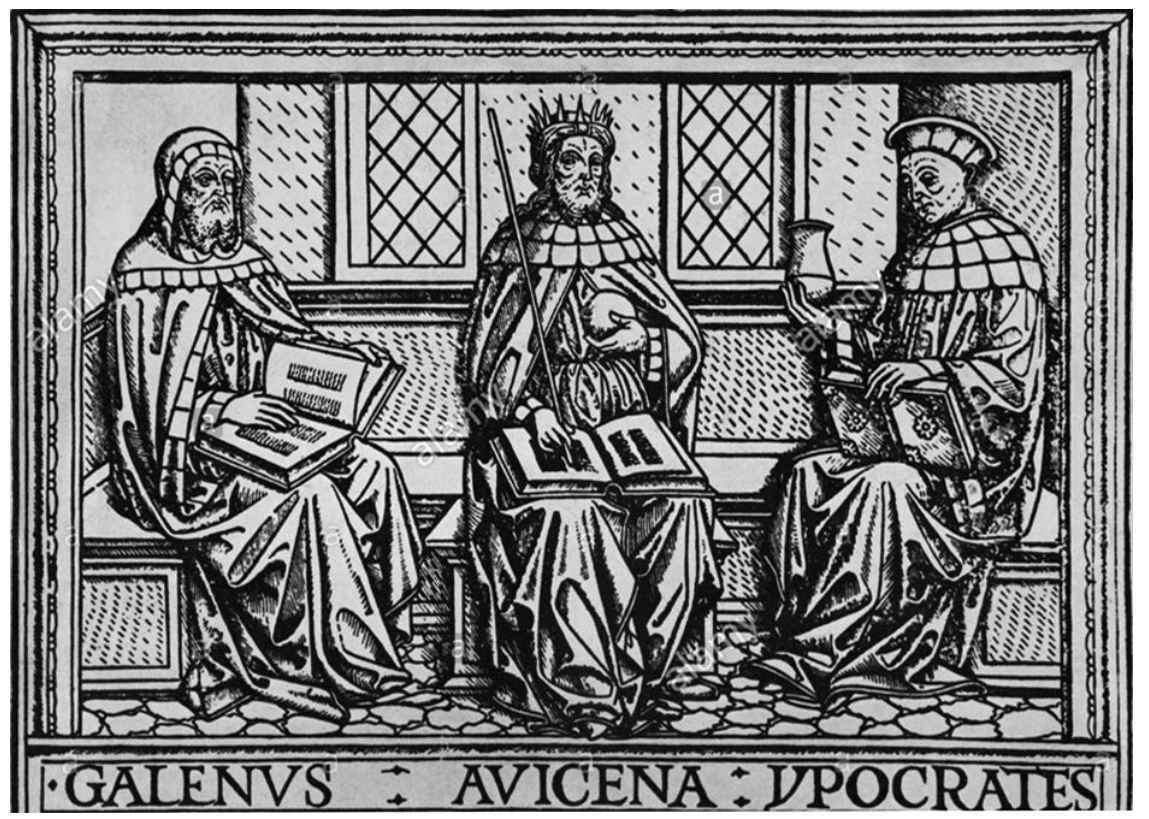

Figure I. Portraits of Galen (left), Avicenna (middle) and Hippocrates (right). The image was obtained on internet, an open source courtesy of the Wellcome Library.

He continued self-education and by the age of $\mathrm{I} 7$ he had mastered Islamic law, medicine, and metaphysics [II, 2I] . At the same age of I7, he was able to treat and cure the king of Bukhhara, Nuh Ibn Mansur (Noor Ibn Mansoor) of an unspecified illness considered incurable by all well-known physicians of the time [2I]. In return, the king offered to reward Ibn Sina for his mighty work but he refused the prize and only asked to use the King's well stocked library. He contributed immensely to the fields of Aristotelian philosophy and medicine during his time [ $\left.\mathrm{I}_{3}, 2 \mathrm{I}, 22\right]$. Avicenna compiled his most influential book of medicine, the Al-Qānün fì al-țibb (The Canon of Medicine) which is ranked amongst the most famous books in the history of medicine [II].

The book is divided into five books which are categorized into separate disciplines of medicine and pharmacy. The anatomical concepts are distributed throughout the book, particularly in the first volume where most of the general anatomy is presented and the rest is presented together with sections describing signs and symptoms of diseases on various organs. The Canon of Medicine was translated into Latin by Gerard of Cremona in the $12^{\text {th }}$ century and into Hebrew in I279 [3, II, I7]. The book was adopted and became the main textbook of medicine in Western medical schools until late ${ }^{6} 5_{5}$ 
[I7]. Avicenna compiled all the medical information available to him from his predecessors including Aristotle, Hippocrates and Galen, and added his own information gained from surgical practice and observations [17]. There is no consensus as to whether Avicenna performed human cadaver dissections or undertook it in secret considering that during his time human dissections were prohibited in the Muslim religion [I7]. However, his findings about the human body were novel for his time. Avicenna recommended that physicians and surgeons base their knowledge on the anatomy of the human body. Avicenna stated, "I believe that at the beginning, pupils should learn the general principles of medicine, both in theory and in practice. Analysis of diseases which affect different organs will precede the methods of keeping these organs in sound health. To satisfy this, we must first study the anatomy of these organs" [I8, 19].

\section{Skeletal System}

\section{Gener al Description on bones AND joints}

Avicenna affirmed that bones and cartilages offer support and protection to body structures, vital organs and also facilitate movement. He distinguished compact bones from cancellous bones. Avicenna classified joints into four types, which include joints with a large and small joint space, embedded joints and sutural joints [19, 20]. This classification concurs with modern descriptions of synovial joints, gomphosis on alveolar surfaces and sutural joints respectively as shown in extant anatomical textbooks [23, 24].

The CRANIUM

Avicenna indicated that the cranium was made up of several bones that varied in density. He noticed that skull bones were light in weight [I9, 25]. The lightness of the skull bones was associated with reduced pressure on the brain. He stated that "The skull bones have been made spongy for the passage of vapours and so as not to be too heavy for the brain" [18-20]. He also noticed that skull bones have foramina for the passage of nerves and vessels to and from the skull. In addition, he described accurately the topography of the various bones of the skull vault including their articulations. He mentioned that:

"The frontal bone is located anteriorly; behind it are two parietal bones which are above the temporal bones and the occipital bone which is more compact and protects the back of the brain posteriorly" [18-20]. 
In the Canon of Medicine, the individual sutures of the cranium were named and described accurately. The squamosal suture was regarded as a false suture that lacks serration but made up of overlapping temporal and parietal bones $[19,20]$.

\section{THE SPINE}

Avicenna described the bones of the vertebra including their functional and biomechanical properties $[3, \mathrm{II}$, I4, I9]. He classified the spine into the cervical, thoracic, lumbar, sacral and coccygeal regions [I9, 20], based on the individual size and shape variation of each vertebra $[3$, II]. This classification is widely accepted in modern anatomy literature. Avicenna critically examined the biomechanics and movements

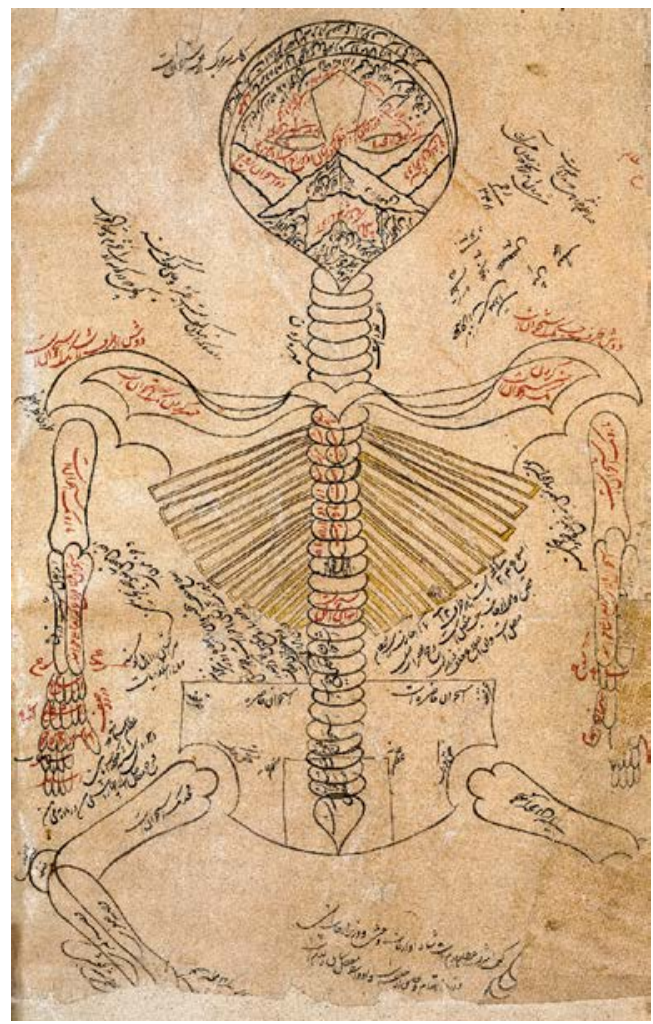

Figure 2. Avicenna's drawing of the skeletal system in the Canon of Medicine. The image was obtained on internet, an open source courtesy of the Wellcome Library. of the spine and also disorders associated with it such as kyphosis [3, II]. He described the $10^{\text {th }}$ thoracic vertebra as the center of rotation of the vertebral spine [II].

\section{The Rib CAge AND STERnUm}

Avicenna mentioned that the skeletal components of the rib cage protect the respiratory organs, heart, upper part of the stomach, and the intestines [18-20]. He further specified that the rib cage was expandable, thereby increasing the diameter of the thorax during inspiration and stomach distension. He noticed that the upper seven ribs were attached to the sternum anteriorly and suggested that the arrangement is crucial for the support of the vital thoracic organs [19, 20]. Avicenna described the ribs attached to sternum (true ribs) separately from those that are not associated with the 
bone (false ribs) [18-20]. His classification of ribs complemented the modern classification into true ribs (from ribs number $\mathrm{I}$ to 7 ) and false ribs (from rib number 8 tor2). In addition, Avicenna described accurately the location of the articular tubercle of the rib on the angle of each rib.

In the Canon of Medicine the sternum was described as a flat bone with an outer layer of cortical bone and a core made of cancellous bone [18-20]. Avicenna acknowledged that the cartilaginous joints between various parts of the sternum facilitate thoracic expansion during respiration $[\mathrm{r} 9,20]$. He also mentioned a cartilaginous process of the sternum (xiphoid process) and its functions in protecting the epigastrium. In modern anatomy the complete ossification of joints between various sternebrae is attained at the age of 25 years $[23,24,26]$ and hence before then the sternum consists of separate bones.

\section{The Clavicle AND scapula}

Avicenna described the clavicle as having both convex and concave parts at its medial and lateral ends respectively. He stated that the hollow space behind the convex inner part of the medial aspect of the clavicle acts as a passage-way for neurovascular structures extending and from the head [I820]. In modern anatomy, the medial convex inner space of the clavicle protects the contents of the carotid sheath [23]. Avicenna described the scapula as thin and flat bone medially and thick on the lateral edge where the bone articulates with the rounded head of the humerus [19, 20]. He described the acromion and the coracoid processes of the scapula and suggested that their functions were to prevent dislocation of the shoulder joint [20]. According to Avicenna, the scapula serves two functions related to the protection of the chest wall posteriorly and facilitation of movement of the arm [18-20]. These descriptions of the scapula are congruent with the modern anatomy literature and additionally the scapula offers attachments to muscles related to the arm and the trunk.

\section{THE HUMERUS AND THE SHOULDER JOINT}

Avicenna described the humerus in agreement with modern anatomy whereby the humerus forms the arm bone with a convex head, a shaft and a distal part with prominences. He described the shoulder joint as a loose movable joint which is often dislocated $[\mathrm{I} 9,20]$. He also described four ligaments contributing to the strength and stability of the shoulder joint including the joint capsule. On the distal portion of the humerus, Avicenna noted that the medial prominence was not involved in the joint formation 
of the elbow but was rather responsible for protecting nerves and vessels [I820]. The most important structure at this level is the ulna nerve which passes posterior to the medial epicondyle of the humerus to enter the forearm [23]. Avicenna described the lateral prominence, the anterior and posterior depressions (which can be inferred to the olecranon and coronoid fossae in modern anatomy) and their involvement in the formation of the elbow joint. He classified the elbow joint as hinge joint, a classification which still holds in modern anatomy literature.

\section{The RAdiUs AND ULnA}

Avicenna indicated that the forearm consists of two bones joined together along their length by a membrane. He noted that the radius allows supination and pronation rotation of the forearm, whereas the ulna participates in flexion and extension of the elbow joint [9, I8, I9]. In addition, he mentioned the head of the radius contains a depression that articulates with the lateral prominences (capitulum) of the distal humerus and is held in place by a ligament $[19,20]$. He described the proximal portion of the ulna bone and its capacity in limiting hyperextension of the elbow. Distally, the styloid processes of the both the ulna and radius were described and their contribution to the attachment of ligaments that support the wrist joint was specified.

\section{THE WRIST AND HAND}

Avicenna mentioned that there are seven carpal bones arranged in two adjoining rows in the wrist with the proximal row containing three bones, while the distal row consists of four bones. He noted that bones in the proximal row articulate with the distal ends of both the radius and ulna; participate in flexion and extension of the wrist joint [18-20]. He further described the eighth bone of the wrist, the pisiform, as a bone located out of the general alignment of the wrist bones and only offers protection to the ulna nerve [18-20]. Avicenna's description of the articulation at the wrist joint was not entirely accurate. The ulna bone does not participate in the wrist joint but rather articulate with the distal portion of the radius proximal to the wrist joint [23].

Avicenna mentioned the correct number of metacarpals and phalanges of the hand and provided insights into their structure and function [9]. He stated that "Metacarpals provide a concave surface for the hand that enables the hand to retain liquids and firmly surround objects" [I8-20]. In addition, Avicenna provided reasons as to why there should be only three phalanges in each finger except the thumb. He argued that: 
"If there had been more than three phalanges, the fingers would have obtained a greater range of movement but they would be weakened in strength. If the phalanges had been two, the fingers would have become stronger but the range of movement would have been restricted; while the fingers need greater movement and nominal strength" [18-20].

Avicenna described the position of the thumb as being appropriate for apposition with other fingers; aiding in grasping objects [18-20].

THe PELVic Bones

Avicenna described the pelvic bones as forming a bony ring; constituted posteriorly by the sacrum, laterally by the two hip bones and anteriorly by the fusion of the two pubic bones. In addition, he identified and described the three parts of the hip bone and their articulations as follows:

"The iliac bone lies outwards and articulates posteriorly with the sacrum; the pubis lies anteriorly and articulates with the bone of the other side through a strong joint, and the ischium lies posteromedial to the ileum and contains the acetabulum, a depression which articulates with the convex head of the femur" [18-20].

Avicenna incorrectly described the acetabulum as a feature of the ischium bone alone; instead it is borne by all three parts of the hip bone.

THE THIGH AND KNEE JOINT

Avicenna indicated that the femur is the largest bone of the body, which is in agreement with modern anatomy. He described the articulation of convex head of the femur with the acetabulum of the hip bone. He described the lateral convexity and medial concavity of the shaft of the femur of which he ascribed the medial concavity to the protection of nerves and vessels from direct impact [18-20]. Distally he described the femoral condyles and their articulation with the tibia to form the knee joint. Avicenna mentioned that the knee joint was strengthened by an internal ligament and two external ligaments located medial and lateral to the joint. Modern anatomy describes two internal ligaments consisting of the anterior and posterior cruciate ligaments, while the external ligaments consist of medial and lateral collateral ligaments [23]. The patella was described as an oval bone that protects the knee joint anteriorly. 


\section{The TIBIA, FIBUla AND THE FOOT}

Avicenna indicated that the fibula is a small bone of the leg located lateral to the tibia and does not articulate with the femur at the knee joint but participates in the articulations at the ankle joint [18-20]. He further described the skeleton of the foot and its adaptions to standing and grasping on uneven surfaces. He mentioned that the foot is made up of 26 bones consisting of 7 tarsals, 5 metatarsals and I4 phalanges [18-20]. He also noted the presence of a variable number of sesamoid bones in the foot. He described and named the talus, calcaneus and cuboid accurately including the joints they make.

\section{Muscular system}

Avicenna described both the functions of the muscles in producing movement and the action of nerves on muscle contraction and relaxation. But he did not precisely describe the muscle attachments and/or their nomenclature. The most significant finding was the differentiation of nerves, tendons and ligaments $[9, \mathrm{I} 2,20,27]$ contrary to Galen's earlier assumptions that nerves and tendons were of the same nature [28]. Avicenna stated that:

"The nerves are derived from the brain or spinal cord. The brain receives sensation through nerves. The nerves provide power and voluntary movements to muscles. The tendons exit from muscles. When muscles are relaxed the tendons become loose and the limb extends. When muscles contract the tendons become tight and the limb flexes" [18-20].

\section{THE MUSCLES OF THE HEAD AND NECK REGION}

Avicenna described the muscles that effect facial movement including dilators and constrictors of orifices such as the orbit, oral cavity and nostrils; and muscles that wrinkle the skin of the face. He noted that facial muscles do not have bony attachments but rather are inserted into the skin. Within the orbit, Avicenna described the six extraocular muscles including their functions which include elevation, depression, adduction, abduction, and rotation of the eyeball [I7-20]. He also mentioned the relationship between the common tendons of origin of some extraocular muscles with the optic nerve $[18-20]$.

Avicenna described the temporalis muscle and its function in elevating the lower jaw. In addition, he described the digastric muscle, its attachments and actions including in association with other infrahyoid muscles [18-20]. Muscles associated with the larynx were also described in the Canon of 
Medicine, but their names were not provided [7, Iо, 29]. Avicenna described the actions of the salpingopharyngeus and palatoglossus in elevating the larynx and pharynx during deglutition [I8-20].

\section{THE THORACIC MUSCLES}

Avicenna described primary and secondary respiratory muscles, particularly those involved during forced respiration. He asserted that respiratory muscles act by expanding and contracting the thoracic wall [18-20]. He described the intercostal muscles as primary muscles of respiration and further expanded on the obliqueness of the fibers of the inner thoracic muscles. He also described secondary respiratory muscles as those muscles attaching the scapula and the cervical vertebra to the thoracic wall.

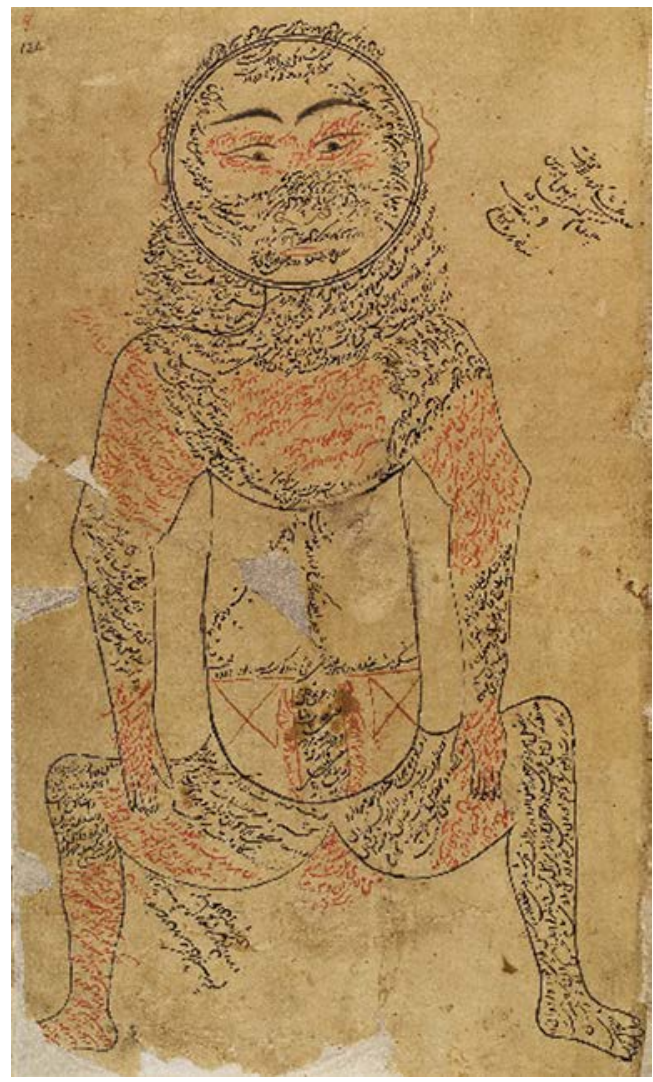

Figure 3. Avicenna's drawing of the muscular system in the Canon of Medicine. The image was obtained on internet, an open source courtesy of the Wellcome Library.

\section{THe LIMB MUSCLES}

Avicenna described the muscles of the upper limbs according to the segment, muscle groups and the joints they act upon [9, I8, 20]. He described five adductors and five abductors of the arm region. The abductors of the arm were described as muscles originating from the scapula and inserting on the humerus. The forearm muscles were described and grouped as extensors, flexors, supinators and pronators. Avicenna distinguished the extrinsic and intrinsic muscles of the hand; extrinsic muscles have their origins in the forearm, whereas intrinsic muscles are integral to the hand. He noted that ther 8 intrinsic hand muscles and finger flexors were arranged in superficial and deep layers [9, I8-20]. 
In the lower limbs, Avicenna described the flexors and extensors of the thigh region [18-20]. He also mentioned knee flexors and extensors, and the insertion of knee joint extensors into the patella. The muscles of the foot were described as 'foot raisers', located anterior to the leg and 'foot depressors' located posterior to the leg; inserting through the achilles tendon [I8$20]$. His description of the movements of the foot corresponds with plantar and dorsiflexors respectively found in modern literature.

\section{Nervous SYstem}

\section{THE CRANIAL NERVES}

Most of Avicenna's descriptions on the structure and function of nerves was adopted from Galen (AD I30-I99). Hence, Avicenna considered nerves as hollow and distributing "animal spirit" to the various parts of the body [I8, I9, 30]. He also considered nerves to be either hard (motor) or soft (sensory) in consistency, and regarded their functions as such. Based on the premise of hollow nerves, Avicenna erroneously considered the olfactory tracts as excretory channels to facilitate the removal of waste from the brain ventricles [I8-20]. Avicenna proposed that cranial nerves consisted of seven pairs of nerves excluding the olfactory nerve [I8-20, 30, 3I]. He identified, enumerated and characterized the cranial nerves based on the foramen through which they exited the skull [3I]. Avicenna described the optic nerve as the first pair of cranial nerves; partially crossing at the optic chiasma and penetrating into each eyeball. The oculomotor nerve was described as the second pair of nerves and innervated the extra-ocular muscles [18-20]. The trigeminal nerve and its divisions were described as the third and fourth pairs of cranial nerves; representing the sensory and motor roots respectively. The facial and vestibulocochlear nerves were regarded as the fifth pair. The trochlear and the abducens nerves were not mentioned.

The sixth pair of cranial nerves consisted of three functionally distinct nerves; all traversing the skull though the jugular foramen [18-20] and these correspond to the glossopharyngeal, vagus and spinal accessory nerves in modern terminology [32]. He described one component as supplying the root of tongue and the pharynx (glossopharyngeal nerve), the second component descending to the shoulder joint to supply the flat muscles of the scapula (the spinal accessory nerve) and the third component (vagus nerve) supplying the structures of the larynx. He also noted that the vagus nerve distributes to the viscera in the thorax and abdomen. Avicenna described the seventh pair 
of cranial nerves (hypoglossal nerve) distributing to the muscles moving the tongue.

\section{THE SPINAL NERVES}

Avicenna mentioned that spinal nerves originate from the spinal cord and convey motor and sensory components of the nervous system. He indicated that the motor and sensory roots of spinal nerves originated separately from the spinal cord and that the spinal cord consisted of two separate parts: the "hard and soft" (motor and sensory respectively) [18-20]. The spinal nerves were grouped into cervical, thoracic, lumbar, sacral and coccygeal nerves; a grouping based on vertebral regions. Avicenna described the innervation of the thoracic intercostal muscles and abdominal muscles. He also described the lumbar sacral plexus and its distribution to the muscles of the lower limbs.

\section{Discussion}

Medieval scholars immensely contributed to the growth of existing medical knowledge by modifying and enriching with continuous addition of their research findings [15]. Anatomy knowledge in particular was regarded as the license towards surgical practice and the learning of practical anatomy was emphasized [I7]. However, there is no known evidence pointing to Avicenna having performed human cadaver dissections. His anatomy concepts are significantly compared with modern anatomy, although with minor differences which can be attributed to the lack of sophisticated equipment to clearly delineate the intricate structures of the human body. In the current review it can be deduced that Avicenna gathered his information on the human through the examination of human skeletons and/or performing animal dissections. In the skeletal systems, Avicenna accurately described the number of bones in each region, the articulations they make, the type of articulations and bone prominences. In modern anatomy the classification of bones, characterization of their projections and muscle insertion points, and joint classification are paramount for understanding body movements and functional biomechanics $[23,26]$. Avicenna also highlighted the importance of bone curvatures in protecting vital neurovascular structures, particularly the clavicle and femoral bones. The functional arrangement of bones in the wrist and the hand in facilitating flexion and grasping movements is also emphasized in both the Canon of Medicine and the modern literature. 
In the Canon of Medicine, the muscles of the human body were grouped according to their functions, i.e. the extensors versus the flexors, muscles of facial expression, muscles of respiration and muscles moving the eyeball [I8]. This classification is still in use today and is important in the diagnosis of injuries to certain groups of muscles. Most importantly Avicenna distinguished nerves, tendons and ligaments. This also helps in the surgical management of disorders associated with structures, such as nerve suturing and tendon and ligament repair; both surgical techniques are reported in the Canon of Medicine [9, 18]. Regenerative medicine is one of the fast growing disciplines of medicine and injured peripheral nerves are sutured and repaired, although the success of re-innervating the target structures is low [33]. Lastly, Avicenna delineated motor fibers from sensory fibers in mixed nerves; an arrangement he observed in both cranial and peripheral nerves. He also enumerated cranial nerves and tracked most part of their courses and target organs. Innervation of body structures is important towards understanding their functions and also in pain management.

In conclusion, although the information was written approximately tooo years ago in the $\mathrm{II}^{\text {th }}$ century, Avicenna's anatomy information is still valid in the modern day and has revolutionized numerus applied subjects on the musculoskeletal system.

\section{Acknowledgements}

The authors are grateful to the anonymous reviewers who have offered constructive ideas for improving the manuscript. We also extend our gratitude to the staff at Ibn Institute of Tibb for the assistance with literature material. 


\section{REFERENCES}

[1] G.S.M. Nezhad, B. Dalfardi, A. Ghanizadeh, S.E. Golzari, Insights into avicenna's knowledge of gastrointestinal medicine and his account of an enema device, Acta medico-historica Adriatica 13(Supplement 2) (2015) 29-40.

[2] P. Mazengenya, R. Bhikha, A critical appraisal of 11th century treatise by Ibn Sina (Avicenna) on the anatomy of the vascular system: Comparison with modern anatomic descriptions, Morphologie 102(337) (2018) 61-68.

[3] P. Mazengenya, R. Bhikha, An Analysis of the Structural and Functional Anatomy of the Spine as Viewed by Avicenna (AD 980-1037), Research Journal of Medical Sciences 1(6) (2016) 676-682.

[4] M. Nejabat, B. Maleki, M. Nimrouzi, A. Mahbodi, A. Salehi, Avicenna and cataracts: a new analysis of contributions to diagnosis and treatment from the canon, Iranian Red Crescent Medical Journal 14(5) (2012) 265.

[5] Z. Moradi, M. Besharat, B. Minaiee, J. Aliasl, Z.P. Yekta, M.N. Toosi, Avicenna's View on the Etiologies of Intestinal Obstruction, Iranian Red Crescent Medical Journal 18(2) (2016).

[6] S.M.A. Madineh, Avicenna's Canon of Medicine and Modern Urology: Part I: Bladder and Its Diseases, Urology journal 5(4) (2008) 284-293.

[7] S. Chitsaz, S.F. Mesbah, L. Yarmohammadi, S. Ashktorab, Avicenna's Anatomical Legacy as Seen Through the Relevant Topics in Modern Anat-omy, Iranian Journal of Medical Sciences 33(1) (2015) 32-35.

[8] M. Mosaddegh, N. Shariatpanahi, M.B. Minaee, M.M. Ahmadian-Attari, Avicenna's view on heart and emotions interaction, International journal of cardiology 162(3) (2013) 256-257.

[9] A. Afshar, A brief report about the concepts of hand disorders in the Canon of Medicine of Avicenna, The Journal of hand surgery 36(9) (2011) 1509-1514.

[10] P. Mazengenya, R. Bhikha, A critique on Avicenna's (AD 980-1037) studies on anatomy of the upper respiratory system and some otorhinolaryngologic concepts, Bangladesh Journal of Medical Science 16(2) (2017) 188-193.

[11] S. Naderi, F. Acar, T. Mertol, M.N. Arda, Functional anatomy of the spine by Avicenna in his eleventh century treatise Al-Qanun fi al-Tibb (The Canons of Medicine), Neurosurgery 52(6) (2003) 1449-1454.

[12] A. Aciduman, U. Er, D. Belen, Peripheral nerve disorders and treatment strategies according to Avicenna in his medical treatise, Canon of medicine, Neurosurgery 64(1) (2009) 172-178.

[13] P. Mazengenya, R. Bhika, The Structure and Function of the Central Nervous System and Sense Organs in the Canon of Medicine by Avicenna, Archives of Iranian Medicine (AIM) 20(1) (2017). 
[14] K.H. Keskinbora, K. Keskinbora, A systematic review of Ibn Sina s (Avicenna) studies: reflections on anatomy, Eur. j. anat (2016) 99-105.

[15] S.E. Golzari, Z.H. Khan, K. Ghabili, H. Hosseinzadeh, H. Soleimanpour, R. Azarfarin, A. Mahmoodpoor, S. Aslanabadi, K. Ansarin, Contributions of medieval Islamic physicians to the history of tracheostomy, Anesthesia \& Analgesia 116(5) (2013) 1123-1132.

[16] P. Mazengenya, R. Bhikha, Revisiting Avicenna's (AD 980-1037) anatomy of the abdominal viscera from the Canon of Medicine, Morphologie (2018).

[17] M.M. Shoja, R.S. Tubbs, The history of anatomy in Persia, Journal of anatomy 210(4) (2007) 359-378.

[18] Avicenna, Canon Medicinae, Berlin: Humboldt University Library of Historical Sciences 1658.

[19] M.H. Shah, The general principles of Avicenna's Canon of Medicine, Naveed Clinic 1966.

[20] L. Bakhtiar, O.C. Gruner, The Canon of Medicine (al-Qānūn Fī'l-ṭibb), Abjad Book Designers \& Builders 1999.

[21] A. Zargaran, A. Mehdizadeh, M.M. Zarshenas, A. Mohagheghzadeh, Avicenna (AD 980-1037), Journal of neurology 259(2) (2012) 389-390.

[22] S.Y. Rahimi, D.E. McDonnell, A. Ahmadian, J.R. Vender, Medieval neurosurgery: contributions from the Middle East, Spain, and Persia, Neurosurg Focus 23(1) (2007) E14.

[23] K.L. Moore, A.F. Dalley, A.M. Agur, Clinically oriented anatomy, Lippincott Williams \& Wilkins 2013.

[24] R. Warwick, P.L. Williams, H. Gray, Gray's anatomy, Longman 1973.

[25] O.C. Gruner, A Treatise on the Canon of Medicine of Avicenna, Incorporating a Translation of the First Book 1984.

[26] C. Gunn, Bones and Joints-E-book: A Guide for Students, Elsevier Health Sciences 2011.

[27] M. Al-Qattan, History of anatomy of the hand and upper limb, The Journal of hand surgery 31(3) (2006) 502.

[28] M. Rang, The story of orthopaedics, WB Saunders Company 2000.

[29] P. Mazengenya, R. Bhikha, An Analysis of Historical Vignettes by Ibn Sina in the Canon of Medicine on the Structure and Function of the Cardiorespiratory Apparatus, Archives of Iranian Medicine 20(6) (2017) 386.

[30] J. Shaw, A history of the enumeration of the cranial nerves by European and British anatomists from the time of Galen to 1895, with comments on nomenclature, Clinical anatomy 5(6) (1992) 466-484. 
[31] M.M. Shoja, N.M. Oyesiku, Clinical anatomy of the cranial nerves, Clinical Anatomy 27(1) (2014) 2-3.

[32] A.R. Crossman, D. Neary, Neuroanatomy E-Book: An Illustrated Colour Text, Elsevier Health Sciences 2014.

[33] P. Mafi, S. Hindocha, M. Dhital, M. Saleh, Suppl 1: Advances of Peripheral Nerve Repair Techniques to Improve Hand Function: A Systematic Review of Literature, The open orthopaedics journal 6 (2012) 60.

\section{SAŽETAK}

Avicena, perzijski muslimanski liječnik koji je na Zapadu poznat pod tim imenom, bio je utjecajan filozof-znanstvenik srednjovjekovnoga islamskog svijeta. Napisao je i sastavio tekst Kanon medicine, knjigu koja je na većini perzijskih $i$ zapadnih sveučilišta prihvaćena kao udžbenik medicine. Knjiga sadrži osnovne medicinske znanosti, primijenjene kliničke znanosti i farmakologiju. U ovom istraživanju predstavljamo analizu anatomije mišićno-koštanog $i$ perifernoga živčanog sustava, kako ju je Avicena predstavio u Kanonu medicine $i$ uspoređujemo ju s modernom literaturom.

Ključne riječi: Avicena; Ibn Sina; mišićno-koštani sustav; periferni živčani sustav; moždani živci; zglobovi 